\title{
EVOLUÇÃO DO USO DA TERRA ENTRE 1996 E 1999 NO MUNICÍPIO DE BOTUCATU-SP
}

\section{SÉRGIO CAMPOS ${ }^{1}$, MARILDA SILVA ${ }^{2}$, EDSON L. PIROLI ${ }^{3}$, LINCOLN G. CARDOSO ${ }^{4}$, ZACARIAS X. BARROS ${ }^{4}$}

RESUMO: Este trabalho teve o objetivo de avaliar a evolução do uso da terra no município de Botucatu - SP, no período de três anos, considerando-se seis tipos de cobertura vegetal (cana-deaçúcar, reflorestamento, floresta nativa, pastagem, cítrus e outros), tendo como base as imagens de satélite Landsat 5, bandas 3; 4 e 5, órbita 220, ponto 76, quadrante A, passagem de 8 de junho de 1999. O Sistema de Informações Geográficas - IDRISI for Windows 3.2, foi utilizado para as análises. Os resultados mostraram que esse programa foi eficiente para auxiliar na identificação e mapeamento das áreas com uso da terra, facilitando o processamento dos dados. As imagens de satélite TM/LANDSAT 5 forneceram um excelente banco de dados para a classificação supervisionada. $O$ município não vem sendo preservado ambientalmente, pois apresenta-se coberto com menos de $20 \%$ de florestas nativas, mínimo exigido por lei. As áreas de pastagem, principal componente da paisagem do município, confirmam a vocação da região para a pecuária.

PALAVRAS-CHAVE: imagem de satélite, geoprocessamento, sensoriamento remoto.

\section{EVOLUTION OF THE LAND USE BETWEEN 1996 AND 1999 AT BOTUCATU MUNICIPALITY - SP, BRAZIL}

SUMMARY: This study aimed to evaluate the evolution of land use at Botucatu Municipality, during three years, considering six vegetative covers (sugar cane, reforestation, native forest, pasture, citrus orchard and others). As data source, a Landsat TM image, bands 3; 4 and 5, orbit 220, point 76, quadrant A, from June 8, 1999 was used. The Geographic Information System (GIS) used to analyze the images was IDRISI for Windows 3.2, and the software was very efficient for identificating and mapping the vegetative cover. The Landsat 5 image was an excellent database for digital classification. The Municipality is not being preserved environmentally, because less than $20 \%$ of its area is covered with native forests, the minimum demanded by law. The pasture for cattle-raising is the predominant land use in the studied area.

KEYWORDS: satellite image, geoprocessing, remote sensing.

\footnotetext{
${ }^{1}$ Prof. Adjunto, Departamento de Engenharia Rural, FCA/UNESP, Caixa Postal 237, Botucatu - SP, Fone: (0XX14) 3811.7165, e-mail: seca@fca.unesp.br

${ }^{2}$ Geógrafa, aluna do Curso de Especialização "Formação de Educadores Ambientais”, Instituto Básico, UNESP, Botucatu - SP.

${ }^{3}$ Aluno de Doutorado do Programa de Pós-Graduação em Agronomia - Área de Concentração Energia na Agricultura, FCA/UNESP, Botucatu - SP.

${ }^{4}$ Prof. Titular, Departamento de Engenharia Rural, FCA/UNESP, Botucatu - SP.

Recebido pelo Conselho Editorial em: 26-11-2001
}

Aprovado pelo Conselho Editorial em: 18-2-2004 


\section{INTRODUÇÃO}

O conhecimento da ocupação do solo e da sua localização em uma determinada região fornecem elementos para o planejamento de uso ambiental e de extração de recursos naturais visando à melhoria da qualidade de vida da população. Os dados experimentais obtidos de imagens orbitais são fundamentais para os estudos no campo científico, principalmente no planejamento de uso da terra, por possuírem um rico e importante potencial de variáveis mensuráveis dos aspectos superficiais do terreno.

A identificação, o mapeamento e a quantificação das ocupações do solo com a análise visual da imagem de satélite são de fundamental importância para os profissionais que dependem de um levantamento mais detalhado dos alvos.

A cobertura vegetal, segundo VIEIRA (1978), tem grande influência nos processos de escoamento, pois atua no regime das águas, nas características do solo e no mecanismo hidrológico, retardando e desviando o escoamento superficial e, conseqüentemente, a erosão.

O conhecimento da ocupação do solo quanto a sua natureza, localização, forma de ocorrência e mudanças ocorridas em determinados períodos são de grande valia para a programação de atividades que visam ao desenvolvimento agrícola, econômico e social da região (POLITANO et al., 1980).

O levantamento do uso atual da terra, necessário para fins de planejamento, pode ser obtido a partir da utilização de dados multiespectrais, fornecidos por satélites de Sensoriamento Remoto, associados às técnicas de interpretação (PEREIRA et al., 1989).

As vantagens de utilizar dados de sensoriamento remoto nos levantamentos do uso atual das terras, segundo FREITAS FILHO (1990), são atingir grandes áreas de difícil acesso e fazer o imageamento a altas altitudes, possibilitando uma visão sinóptica da superfície terrestre, com repetitividade, viabilizando, portanto, a ações de monitoramento.

SANTOS et al. (1993) comentam que o uso de imagens de satélite como base cartográfica é muito promissor, devido ao seu relativo baixo custo, fácil aquisição, periodicidade de aquisição e fornecimento de importantes informações sobre mudanças no uso da terra.

CRÓSTA (1992) afirma que, na classificação supervisionada, é necessário que o usuário tenha conhecimento prévio da área a ser classificada. Esse tipo de observação é chamado de verdade terrestre. Essas áreas podem ser usadas como padrão de comparação, com a qual todos os "pixels" desconhecidos da imagem serão comparados para decidir a qual classe pertencem. A área da imagem que o usuário identifica como representativa de uma das classes é chamada área de treinamento.

Nesse contexto, o presente trabalho foi desenvolvido com o objetivo de estudar a evolução do uso da terra no município de Botucatu - SP, no período de 1996 a 1999.

\section{MATERIAL E MÉTODOS}

A área de estudo compreende o município de Botucatu - SP, situado na região Centro-Sul a $232 \mathrm{~km}$ da Capital do Estado de São Paulo. Está delimitada pelas coordenadas geográficas, longitudes

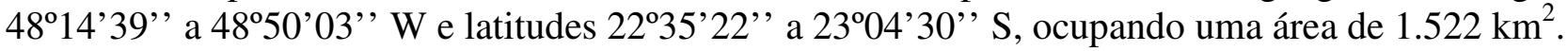

O clima do município é, segundo a classificação de Köeppen, tipo Cfa, com clima temperado chuvoso e com a direção dos ventos predominantes sudeste/noroeste (SE/NW). De acordo com MARTINS (1989), a temperatura média anual na região é de $20,2^{\circ} \mathrm{C}$, sendo as temperaturas médias dos meses mais quentes de $23,2{ }^{\circ} \mathrm{C}$ e dos meses mais frios de $16,9^{\circ} \mathrm{C}$. 
A precipitação média anual é de $1.447 \mathrm{~mm}$, ocorrendo uma precipitação média nos meses mais chuvosos de 223,4 mm e no mês mais seco de $37,8 \mathrm{~mm}$. As temperaturas máximas absolutas não assumem valores excessivamente altos, privilegiando a região com verão ameno.

Os solos do município (OLIVEIRA et al., 1999) são derivados do arenito e do basalto, com o predomínio dos arenitos. Os principais são:

- Neossolos Quartzarênicos (RQ): são solos de baixa fertilidade com baixa capacidade de retenção de água, derivados do arenito Botucatu, muito suscetíveis à erosão e localizam-se ao norte do município. A sua ocupação atual tem predominância de pastagens e de reflorestamento com eucalipto. Nessas áreas, a ocorrência de voçorocas é freqüente.

- Latossolos Vermelho-Amarelos (LVA): são solos profundos de textura leve, bem drenados, com fertilidade baixa e alta suscetibilidade à erosão. No município, aparecem em ampla faixa ao sul, pequena faixa ao norte da parte frontal da "Cuesta"; ocorrem em áreas de relevo suave a ondulado, e a cobertura vegetal tem predominância de campo e cerrado. A ocupação atual é composta predominantemente por eucaliptos, pastagens e frutíferas diversas.

- Neossolos Litólicos (RL): apresentam textura argilosa, ocorrem em relevo montanhoso; são solos pouco desenvolvidos e, no município, aparecem em toda a extensão da "Cuesta". A profundidade é mínima, com vertentes dos vales muito íngremes e de forma convexa. A vegetação nativa tem predominância da fisionomia latifoliada tropical. São solos com abundantes afloramentos de rochas e pouco adequados para agricultura.

- Latossolos Vermelhos (LV): com textura argilosa, são solos profundos, bem drenados, formados a partir de rochas basálticas. No município, aparecem ao longo da Bacia do Rio Pardo e Rio Lavapés. A vegetação original é de Mata Atlântica, da qual restam pequenos fragmentos. São adequados para a cultura do café e culturas anuais (feijão, milho, olerícolas e pastagens).

O relevo e a geomorfologia do município de Botucatu caracterizam-se por três regiões fisiográficas distintas denominadas Depressão Periférica, reverso e front da "Cuesta". As altitudes variam de $650 \mathrm{~m}$ a $950 \mathrm{~m}$ em relação ao nível do mar. O município de Botucatu é drenado por duas bacias hidrográficas: a do Rio Tietê, ao norte, e a do Rio Pardo, ao sul.

Para a delimitação das divisas do município, foram utilizadas cartas topográficas na escala 1:50.000, com eqüidistâncias verticais de $20 \mathrm{~m}$, editadas pelo Instituto Brasileiro de Geografia e Estatística (IBGE). Utilizou-se das cartas topográficas de Botucatu (SF-22-R-IV-3); Pratânia (SF-22Z-B-V-4); Itatinga (SF-22-Z-D-II-2); Barra Bonita (SF-22-Z-B-IV-1); Santa Maria da Serra (SF-22-ZB-VI-2); São Manoel (SF-22-Z-B-V-2) e Pardinho (SF-22-X-II-1) editadas em 1973. Para a entrada dos dados, utilizou-se do Scanner Genius Vivid Pro II e da digitalização na tela.

Como fonte de dados, foi utilizada a imagem de satélite nas bandas 3; 4 e 5, correspondentes às regiões do espectro visível, do infravermelho próximo e médio do Sensor TM, do LANDSAT 5, órbita 220, ponto 76, quadrante A, passagem de 8 de junho de 1999, para elaboração da carta de uso da terra do município de Botucatu. O Sistema de Informações Geográficas - IDRISI for Windows 3.2 foi usado para as análises. Na coleta e confirmação das coordenadas dos pontos de controle a campo, foi utilizado um GPS de Navegação Garmin XL 45.

Inicialmente, uma composição falsa-cor foi elaborada com a combinação das bandas 3; 4 e 5, nas cores azul, verde e vermelha, respectivamente, pois essa apresenta uma boa discriminação visual dos alvos, possibilitando a identificação dos padrões de uso da terra de maneira lógica. Essa composição apresenta os corpos d'água em tons azulados, as florestas e outras formas de vegetações em tons esverdeados e os solos expostos em tons avermelhados. 
O georreferenciamento da composição falsa-cor foi realizado por meio do módulo "Reformat/Resample" do SIG-IDRISI. Os pontos de controle para o georreferenciamento foram obtidos nas cartas topográficas e confirmados in loco no campo com o GPS. Após o georreferenciamento, foi feito o recorte da área do município de Botucatu e demarcadas as áreas de treinamento sobre a imagem com o cursor e o mouse em vários locais, procurando-se abranger todas as variações de cada ocupação do solo.

Para o georreferenciamento da imagem digital, utilizou-se de dois arquivos de pontos de controle. O primeiro foi criado usando a imagem digital e o outro, a carta topográfica. Os pontos de controle foram escolhidos de forma que cada um deles fosse facilmente identificado, tanto na imagem digital, como na carta topográfica. Foram determinadas as coordenadas de cada ponto e, com esses dados, foi feito um arquivo de correspondência, sendo colocadas inicialmente as antigas coordenadas (carta topográfica) e, em seguida, as novas coordenadas (imagem) para cada ponto escolhido, por meio do comando "Edit" do menu "Database Query", presente no módulo "Analysis". Para escolher a equação de melhor ajuste entre os dois sistemas de referência, foi utilizado o menu "Resample" do módulo "Reformat", o qual faz a reamostragem e a correção geométrica dos pontos de controle.

Em seguida, foram criadas as assinaturas pelo módulo "Makesig" e, depois, a classificação supervisionada propriamente dita pelo método de Máxima Verossimilhança, através do módulo "Maxlike".

Na classificação supervisionada, as classes de uso da terra foram identificadas e diferenciadas em seis classes de usos das terras representadas por cana-de-açúcar, reflorestamento, floresta nativa, pastagem, cítrus e outros. Nessa fase, usaram-se seus padrões de resposta espectral. As áreas de treinamento foram delimitadas por polígonos desenhados sobre cada classe de uso da terra na imagem. Em seguida, foram indicadas as assinaturas para cada classe de uso da terra, criando-se um arquivo de assinaturas para todas as categorias. A imagem foi classificada com base nesses dados, e as amostras de usos das terras duvidosas foram confirmadas a campo com uso do GPS.

A verificação do resultado da classificação foi avaliada estatisticamente por meio do Índice de Kappa. O procedimento sugerido por EASTMANN (1999) e por SIMÕES (2001), inicialmente, consistiu na geração de pontos aleatoriamente estratificados. O uso da terra no "pixel" referente a cada ponto foi identificado, sendo criado a seguir um arquivo de valores relacionado aos pontos amostrais da verdade terrestre. Esses dois arquivos foram associados e, em seguida, rasterizados, gerando uma imagem raster com a verdade terrestre. A seguir, por meio do módulo Ermat, analisou-se estatisticamente a classificação supervisionada, confrontando-a com a imagem contendo a verdade terrestre com a imagem classificada do uso da terra. O resultado dessa confrontação é uma matriz de erros e o índice de Kappa geral e por categoria.

As áreas dos usos das terras de Botucatu - SP, foram determinadas utilizando o comando "Área" do menu "Database Query", pertencente ao módulo "Analysis", e posteriormente foram também determinadas as porcentagens de cada classe.

Para a identificação dos alvos em suas cores reais, foram utilizadas as chaves de interpretação para imagens, propostas por ROCHA (1986).

Como fonte de dados para a obtenção do uso da terra em 1996, foi utilizado o levantamento do Projeto Lupa, referente aos anos de 1995 e 1996, fornecido pela Secretaria de Agricultura e Abastecimento do Estado de São Paulo. Desse levantamento, foram também obtidas as áreas com as coberturas vegetais do tipo cana-de-açúcar, reflorestamento, floresta nativa, pastagens, cítrus e outros (café, cidade, culturas anuais e perenes, etc.). 


\section{RESULTADOS E DISCUSSÃO}

O mapa de classificação digital supervisionada (Figura 1), obtido da imagem de satélite do LANDSAT em 1999, permitiu constatar a existência de seis classes de uso representativas: cana-deaçúcar, reflorestamento, floresta nativa, pastagem, cítrus e outros.

Os usos das terras (Figura 1 e Tabela 1) observados pelo exame visual na imagem de satélite indicam que praticamente $25 \%$ da área de estudo era coberta por pastagens em 1999, ou seja, 37.301,06 ha, comprovando a vocação da região para a pecuária (CAMPOS, 1993).

A cobertura florestal, representada por florestas nativas e reflorestamento, predominou em $20,73 \%$ da área total do município, sendo 7,47\% com reflorestamento e 13,26\% com florestas nativas. Essas florestas nativas são formadas por vegetações arbóreas, ou seja, matas ciliares, cerrados e florestas propriamente ditas. Segundo o Código Florestal (1965), a reserva mínima de florestas deve ser de $20 \%$. Assim, nota-se uma deficiência de reflorestamento da ordem de $6,74 \%$.

Observa-se que as florestas nativas ocorrentes na área de estudo (Figura 1) são, em sua grande maioria, representadas por matas ciliares. Isso permite inferir que não houve intervenção humana nesses locais devido à proteção dada pela Legislação Florestal vigente, pois o Código Florestal define essas áreas situadas às margens de cursos d' água, rios e ao redor de nascentes como áreas de preservação permanente.

Os reflorestamentos (pínus, eucalipto, etc.), outra cobertura florestal muito significativa no município de Botucatu, apresentam grande importância econômica, fornecendo matéria-prima para as indústrias de beneficiamento de madeiras e de produtos derivados, como chapas de fibra, aglomerados e compensados. Esse uso da terra e as atividades derivadas vêm gerando empregos e contribuindo para o desenvolvimento econômico e social dos municípios da região.

A cana-de-açúcar, embora seja uma cultura de retorno econômico rápido, ocupa uma pequena área do município, ou seja, 8.313,69 ha (5,46\%), ao contrário dos municípios vizinhos, que apresentam grandes áreas cobertas pela cultura canavieira (BARROS et al., 1987; CARDOSO, 1988).

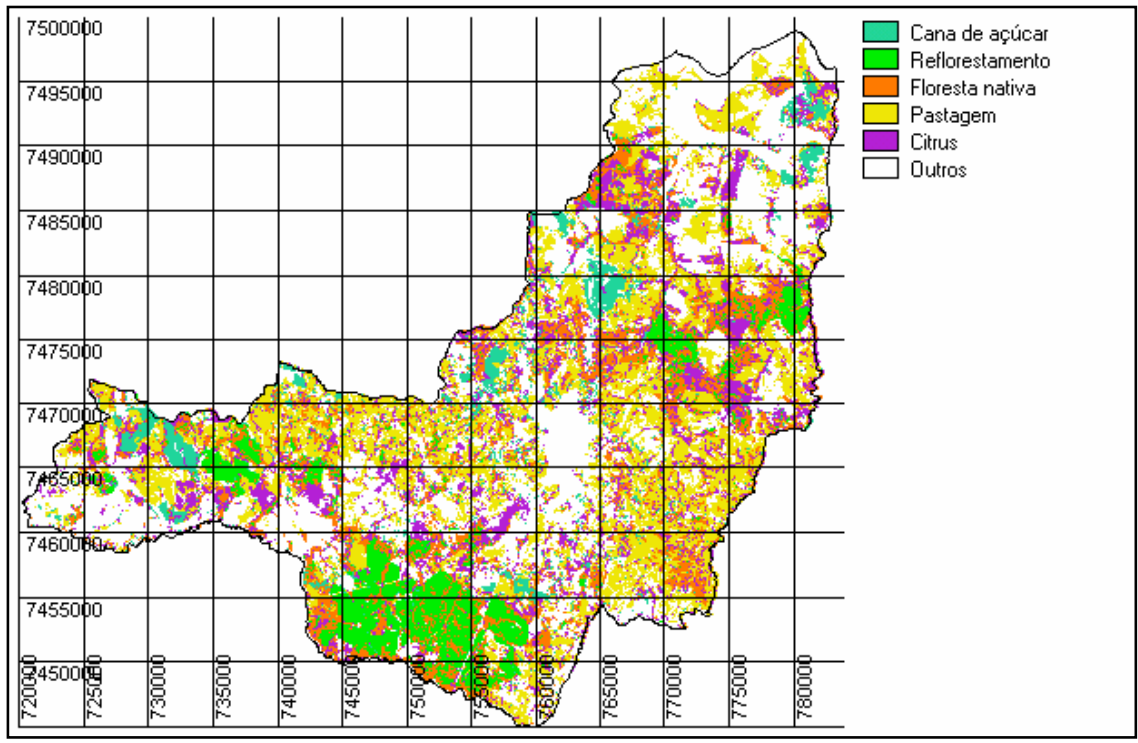

FIGURA 1. Mapa da classificação digital supervisionada do uso das terras do município de Botucatu SP, em 1999, obtido por meio do Sistema de Informações Geográficas - IDRISI. 
A cobertura vegetal sofre modificações constantes com a ação do ser humano, sendo mais intensa essa dinâmica nos solos com melhor fertilidade e de condições ecológicas mais propícias para a exploração agrícola. Contudo, com o aumento da densidade demográfica e o aperfeiçoamento das técnicas agronômicas, os solos mais pobres também vêm sendo utilizados para atividades agropecuárias.

Esse fato já está ocorrendo na região de Botucatu, onde áreas ocupadas em épocas remotas com matas foram ocupadas por pastagens e culturas de rápido retorno econômico para o produtor rural, como é o caso da cana-de-açúcar e, mais recentemente, por cítrus.

A ocupação do solo, como se pode verificar por meio da Tabela 1, que apresenta as porcentagens de redução/ampliação das coberturas vegetais no período estudado no município de Botucatu, permitiu inferir que as pastagens que ocupavam a maior parte da área, quase 50\% do município em 1996, sofreram uma redução, passando a ocupar aproximadamente 25\%, em 1999.

TABELA 1. Usos das terras constatados no período de 1996 a 1999.

\begin{tabular}{|c|c|c|c|c|c|}
\hline \multirow{3}{*}{ Classes de Uso da Terra } & \multicolumn{5}{|c|}{ Área em Relação ao Município } \\
\hline & \multicolumn{2}{|c|}{1996} & \multicolumn{2}{|c|}{1999} & \multirow{2}{*}{$\begin{array}{c}\text { Redução (R) ou } \\
\text { Ampliação (A) } \\
\%\end{array}$} \\
\hline & ha & $\%$ & ha & $\%$ & \\
\hline Cana-de-açúcar & $11.877,30$ & 7,80 & $8.313,69$ & 5,46 & $2,34(\mathrm{R})$ \\
\hline Reflorestamento & $19.241,20$ & 12,64 & $11.374,50$ & 7,47 & $5,17(\mathrm{R})$ \\
\hline Floresta Nativa & $18.379,70$ & 12,08 & $20.183,44$ & 13,26 & $1,18(\mathrm{~A})$ \\
\hline Pastagem & $67.679,80$ & 44,47 & $37.301,06$ & 24,51 & $19,96(\mathrm{R})$ \\
\hline Cítrus & $7.694,00$ & 5,06 & $18.798,06$ & 12,35 & $7,29(\mathrm{~A})$ \\
\hline Outros & $27.328,00$ & 17,95 & $56.229,25$ & 36,95 & $19,00(\mathrm{~A})$ \\
\hline Total & $152.200,00$ & 100,00 & $152.200,00$ & 100,00 & - \\
\hline
\end{tabular}

Essa redução, provavelmente, vem acontecendo por causa do aumento da área implantada com ctrús, que vem ocupando os espaços deixados pelas pastagens. Os cítrus, no período, sofreram uma ampliação de área da ordem de 7,29\% (11.104,06 ha).

As coberturas vegetais, cana-de-açúcar e reflorestamento, sofreram uma redução, respectivamente, de 2,34\% (3.563,61 ha) e 5,17\% (7.866,70 ha) em relação à área do município.

As florestas nativas, de maneira geral, ocorrem em pequenas áreas por toda a extensão do município, porém, com maior concentração nas áreas com relevo acentuado, onde as condições para mecanização são dificultadas porque o acesso é difícil. As florestas nativas apresentaram um aumento de 1,18\% (1.803,74 ha) no período, passando de 12,08\% da área do município em 1996 para 13,26\% em 1999, provavelmente devido à regeneração de algumas áreas desmatadas em épocas remotas, principalmente áreas situadas às margens de cursos d'águas, rios e ao redor de nascentes, que foram deixadas em repouso, transformando-se em matas ciliares, que hoje são consideradas como áreas de preservação permanente pelo Código Florestal.

As imagens de satélites têm condições de oferecer uma visão clara, abrangente e atual do uso da terra. A discriminação, o mapeamento e a quantificação das áreas de uso da terra por meio da classificação supervisionada pelo Sistema de Informações Geográficas (SIG) - IDRISI 32, permitiu obter resultados com maior agilidade quanto à integração e manipulação das áreas.

A avaliação da exatidão para a classificação supervisionada realizada pelo Índice Kappa foi de 0,45, cuja qualidade foi classificada como boa, segundo LANDIS \& KOCH (1977). Como foi possível 
analisar somente seis classes de uso, pode-se concluir que é necessária a aplicação de uma classificação supervisionada mais rigorosa para mapeamentos futuros nessa área.

\section{CONCLUSÕES}

As imagens obtidas do Sensor TM do LANDSAT 5 permitiram o mapeamento do uso da terra no município de Botucatu e forneceram um banco de dados para a classificação supervisionada do uso da terra e futuros planejamentos e gerenciamento das atividades regionais. O SIG-IDRISI permitiu constatar e classificar, por meio de seus diferentes módulos para georreferenciamento e classificação digital, as áreas de usos das terras com rapidez. O município de Botucatu não vem sendo preservado ambientalmente, pois apresenta-se coberto com menos de $20 \%$ de floresta nativa, mínimo exigido pelo Código Florestal vigente. A pastagem, principal componente da paisagem do município, devido à predominância de solos arenosos com baixa fertilidade, predominam em $25 \%$, confirmando o domínio da agropecuária.

\section{REFERÊNCIAS BIBLIOGRÁFICAS}

BARROS, Z.X. de; CARDOSO, L.G.; TARGA, L.A. Utilização de fotografias aéreas em ocupação do solo por cobertura vegetal. In: CONGRESSO BRASILEIRO DE ENGENHARIA AGRÍCOLA, 16., 1987, Jundiaí. Anais... Jundiaí: Sociedade Brasileira de Engenharia Agrícola, 1987. p.598-603.

CAMPOS, S. Fotointerpretação da ocupação do solo e suas influências sobre a rede de drenagem da bacia do Rio Capivara - Botucatu (SP), no período de 1962 a 1977. 1993. 164 f. Tese (Doutorado em Energia na Agricultura) - Faculdade de Ciências Agronômicas, Universidade Estadual Paulista, Botucatu, 1993.

CARDOSO, L.G. Comportamento das redes de drenagem em solos com cana-de-açúcar e com eucalipto. 1988. 139 f. Tese (Doutorado em Energia na Agricultura) - Faculdade de Ciências Agronômicas, Universidade Estadual Paulista, Botucatu, 1988.

CRÓSTA, A.P. Processamento digital de imagens de sensoriamento remoto. Campinas: UNICAMP, 1992. $170 \mathrm{p}$.

EASTMAN, J.R. IDRISI 32. Guide to GIS and image processing. Massachusettes: Clark University, 1999. v.2, 169 p.

FREITAS FILHO, M.R.; MEDEIROS, J.S. Análise multitemporal da cobertura vegetal em parte da Chapada do Araripe- CE, utilizando técnicas de Sensoriamento Remoto e Geoprocessamento. In: SIMPÓSIO BRASILEIRO DE SENSORIAMENTO REMOTO, 7., 1993, São José dos Campos. Anais... São José dos Campos: Instituto Nacional de Pesquisas Espaciais, 1993. p.73-80.

LANDIS, J.R.; KOCH, G.G. The measurement of observer agreement for categorical data. Biometrics, Washington, v.33, n.1, p.159-74, 1977.

MARTINS, D. Clima da região de Botucatu. In: ENCONTRO DE ESTUDOS SOBRE A AGROPECUÁriA NA REGIÃO DE BOTUCATU, 1., 1989, Botucatu. Anais... Botucatu: UNESP, 1989. p.8-19.

OLIVEIRA, J.B. de; CAMARGO, M.N.; ROSSI, M.; CALDERAN FILHO. Mapa pedológico do Estado de São Paulo. Campinas: Empresa Brasileira de Pesquisa Agropecuária, 1999. 64 p.

PEREIRA, M.N.; KURKDJIAN, M.L.N.O. de; FORESTI, C. Cobertura e uso da terra através de Sensoriamento Remoto. São José dos Campos: Instituto Nacional de Pesquisas Espaciais, 1989. 118 p.

POLITANO, W.; CORSINI, P.C.; VASQUES, J.G. Ocupação do solo no município de Jaboticabal SP. Científica, São Paulo, v.8, n.1/2, p.27-34, 1980. 
ROCHA, J.S.M. da. Manual de interpretação de aerofotogramas. Santa Maria: Universidade Federal de Santa Maria, 1986, 58 p. (Fascículo XI)

SANTOS, M.L.M.; MATTOS, M.M.; PIRES, I.O.; BROWN, I.F.; ASSIS, W.S. Utilização de imagens de satélite no mapeamento preliminar do uso da terra e na capacitação de agricultores do médio Rio Capim - Paragominas - PA, Brasil. In: SIMPÓSIO BRASILEIRO DE SENSORIAMENTO REMOTO, 7., 1993, São José dos Campos. Anais... São José dos Campos: Instituto Nacional de Pesquisas Espaciais, 1993. 15 p.

SIMÕES, L.B. Integração entre um modelo de simulação hidrológica e Sistema de Informação Geográfica na delimitação de zonas de tampão ripárias. 2001. $171 \mathrm{f}$. Tese (Doutorado em Energia na Agricultura) - Faculdade de Ciências Agronômicas, Universidade Estadual Paulista, Botucatu, 2001.

VIEIRA, N.M. Estudo geomorfológico das voçorocas de Franca - SP. 1978. 225 f. Tese (Doutorado em História) - Instituto de História e Serviço Social, Universidade Estadual Paulista, Franca, 1978. 